\title{
Effect of co-administration of voglibose and vildagliptin on diabetic albino rats
}

\author{
Umashanker PD Keshri*, Mukesh Kumar, Bhulan PD Loc, Manju Gari, \\ Janardan Sharma, Rajiv Kumar
}

Department of Pharmacology, RIMS, Ranchi, India

Received: 28 May 2016 Accepted: 01 July 2016

*Correspondence to:

Dr. Umashanker PD Keshri, Email: ruma_shanke@ rediffmail.com

Copyright: (C) the author(s), publisher and licensee Medip Academy. This is an openaccess article distributed under the terms of the Creative Commons Attribution NonCommercial License, which permits unrestricted noncommercial use, distribution, and reproduction in any medium, provided the original work is properly cited.

\begin{abstract}
Background: The progressive nature of type 2 diabetes usually requires a combination of two or more oral agents in long term. Studies have been done to support its relevance. This study was made to observe the possible additive or supra-additive effect of the co-administration of voglibose and vildagliptin expecting it to be beneficial by enhancing the peptide GLP-1 activity which in turn increases insulin secretion while decreasing that of glucagon in response to rise in plasma glucose.

Methods: Healthy male wistar rats weighing 150-250 grams were taken for this study. The animals were divided into five groups, six animals in each group. These groups were normal control, diabetic control, vildagliptin treated, voglibose treated and by vildagliptin and voglibose (co-administered) treated group diabetic rats. Diabetes was induced by freshly prepared nicotinamide followed by streptozotocin intraperitoneal injection. The fasting blood samples were determined by glucose oxidase method. One way ANOVA test was used to compare the effect of drugs on different group.

Results: Fasting blood glucose in normal control was found static. Diabetic rats fasting blood glucose level subsequently increased in different weeks. The animal treated by vildagliptin and voglibose orally has a better control of FBS in comparison to diabetic control group. The animal treated by coadministration of vildagliptin and voglibose had a better effect than vildagliptin treated group and voglibose treated animal.

Conclusions: Vildagliptin and voglibose are effective in lowering blood glucose level in albino diabetic rats but their combination has potentiating effect.
\end{abstract}

Keywords: Voglibose, Vildagliptin, Nicotinamide, Streptozotocin

\section{INTRODUCTION}

Diabetes is one of the common diseases whose prevalence is increasing fastly worldwide. Its prevalence was estimated to be $2.8 \%$ in 2000 and $4.4 \%$ in $2030 .{ }^{1}$ Insulin and oral hypoglycaemic agents like sulfonylurea, biguanides and thiazolidinediones are the major drugs in the management of this disease. However, complete cure of the disease has been eluding physicians for centuries and the quest for the development of more effective antidiabetic agents is pursued relentlessly.

In this context, newer antidiabetic drugs like $\alpha$ glucosidase inhibitors (acarbose, miglitol and most newer drug voglibose) and gliptins (sitagliptin, vildagliptin, saxagliptin and linagliptin) are being proven as milestones in treating diabetes.

Alpha glucosidase inhibitor, voglibose is an important drugs in the management of diabetes mellitus. It has least gastrointestinal symptoms as compared to other $\alpha$ glucosidase inhibitor like acarbose. ${ }^{2}$ It can also be used in combination with other oral antidiabetic agents and insulin. Vildagliptin and other DPP-4 inhibitors may play an important role in the management and preservation of T2DM, particularly being valuable in preventing the development and progression of the disease, which has not been possible till now with any other antidiabetic agents. $^{3,4}$ 
Oral therapy for type 2 diabetes, when used appropriately, should safely assist patients to achieve glycemic target with desired effectiveness and tolerability. Therefore, the progressive nature of type 2 diabetes usually requires a combination of two or more oral agents in long term.

Few previous studies have been done to support its relevance. Yamaguchi $\mathrm{M}$ et al. assessed therapeutic role of vildagliptin and voglibose and their combination. ${ }^{5}$ They found co-administration led to remarkably better pharmacodynamics response compared with each treatment alone, including higher active GLP-1 and lower glucose levels. Though level of vildagliptin decreased when co-administered but the extent of DPP-4 inhibition remains unchanged. ${ }^{5}$ Better efficacy and tolerability was found when it was given for long period and helped in alleviating undesired consequences and progression of diabetic complications. ${ }^{6}$

Supported literature regarding this are few; so this study was done to compare the antihyperglycemic effect of voglibose and vildagliptin in co-administration with each individual drug alone.

\section{METHODS}

Healthy male wistar rats weighing between 150-250 grams were taken for this study. The animals were kept in clean and dry cages, with $12: 12$ hours light-dark cycle at room temperature $\left(\sim 24-28^{\circ} \mathrm{C}\right)$. They were acclimatized to the available housing condition for a period of 1 month. Rats were fed with standard laboratory diet consisting of soaked black gram and soyabean, commercial pellets and water was given ad libitum. The whole experiment was conducted in accordance with ethical norms approved by institutional animal ethics committee (IAEC) guidelines. Only the healthy rats having fasting blood glucose of 200- $250 \mathrm{mg} / \mathrm{dl}$ were included in this study.

The animals were divided into five groups, six animals in each group. These groups are normal control which were treated by $1 \%$ gum acacia, diabetic control group which were also treated with placebo $1 \%$ gum acacia after inducing diabetes by streptozotocin, vildagliptin treated group, voglibose treated group and by both vildagliptin and voglibose (both the drugs were co-administered) treated group in streptozotocin induced diabetic rats. The rats were kept in different cages. All the cages were appropriately labelled. Animals in each cage were also labelled separately and colour coded with the help of permanent marker.

After allowing 7 days for the induction and stabilization of diabetes, drugs were administered from $7^{\text {th }}$ day and this was considered as day 0 for the treatment of group B, C, $\mathrm{D}$ and $\mathrm{E}$. The dose of the drugs was calculated on the basis of body surface area. ${ }^{7}$ Before starting treatment, fasting blood glucose levels for day 0 were estimated for all groups including group A. All the treatments were carried out for a period of 28 days. The fasting blood samples were collected from all the groups on further days $7,14,21$ and 28 day to determine the glucose level by glucose oxidase method using accu chek active glucometer.

\section{Estimation of blood glucose}

For the estimation of fasting blood glucose, the rats were kept deprived of food overnight and were allowed free access to water. Blood samples were collected from the tail of rat. The tail of rat was cleaned with spirit cotton and then it was cut $0.5 \mathrm{~mm}$ just enough to allow one drop of blood to ooze out. One drop of blood was allowed on the appropriate reaction zone of the strip. The level of fasting blood sugar was recorded and noted down in the master chart. After taking the blood sample betadine ointment, using fresh cotton piece was applied to tail of each rat to prevent any infection.

\section{Drugs}

The information related to drugs and chemicals are as follows

- Voglibose (tablet Vogli 0.3 milligram, CIPLA Pharmaceuticals)

- Vildagliptin (tablet Jalra 50 milligram, Novartis India)

- $\quad$ Streptozotocin (STZ)-(Streptozocin sterile powder) 1 gm vial, HIMEDIA, Patna

- Nicotinamide, 100 gram powder, ANIMED, Kolkata.

\section{Preparation of the drugs}

The tablet voglibose was powdered and a uniform suspension was made using $1 \%$ gum acacia in a concentration of $0.005 \mathrm{mg} / \mathrm{ml}$ as required per dose. Since daily dose requirement of 200 gram rat (standard) is 0.01 $\mathrm{mg}$, this was made by dissolving $0.3 \mathrm{mg}$ voglibose tablet in $60 \mathrm{ml}$ of $1 \%$ gum acacia suspension, so that $1 \mathrm{ml}$ contained $0.005 \mathrm{mg}(0.3 \mathrm{mg}$ multiplied by 0.018$)$ of the drug. After weighing each rat of this test group, drug was titrated and delivered orally twice daily using gavage tube. Only freshly prepared suspensions were used each day.

The tablet vildagliptin was powdered and a uniform suspension was made using $1 \%$ gum acacia. This was prepared by $50 \mathrm{mg}$ of tablet dissolving in $50 \mathrm{ml}$ of gum

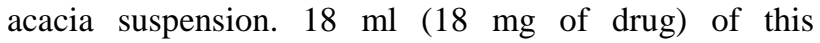
suspension was diluted with addition $2 \mathrm{ml}$ of deionized water to make $20 \mathrm{ml}$ of suspension. This contained $18 \mathrm{mg}$ in $20 \mathrm{ml}$ of suspension so that $1 \mathrm{ml}$ contain desired 0.9 $\mathrm{mg}(50 \mathrm{mg}$ multiplied by 0.018$)$ of drug. Now according to weight of each rat of this test group, drug was titrated and administered using gavage tube. Only freshly prepared suspensions were used each day. 


\section{Co-administration of voglibose and vildagliptin}

$0.005 \mathrm{mg} / \mathrm{ml}$ of voglibose and $0.9 \mathrm{mg} / \mathrm{ml}$ of vildagliptin as prepared above was administered twice daily to group E rats every day from day 0 to day 28 on morning and evening time. According to weight of rats of this test group, drug was titrated and administered using gavage tube.

\section{Preparation of 0.1 M citrate buffer ${ }^{8}$}

For stability of streptozotocin, the ideal $\mathrm{pH}$ range to be obtained was $4.0-4.5$. For this, $31.5 \mathrm{ml}$ of citric acid was mixed with $18.5 \mathrm{ml}$ of sodium citrate and this volume was adjusted to $100 \mathrm{ml}$ by adding deionized water. The $\mathrm{pH}$ of this solution was found 4.2.

Streptozotocin was dissolved in $0.1 \mathrm{M}$ citrate buffer with $\mathrm{pH} 4.2$ and kept in $2-8^{\circ} \mathrm{C}$. It was kept away from light and was injected intraperitoneally to rat at dose of 60 $\mathrm{mg} / \mathrm{kg}$ body weight with the help of disposable $1 \mathrm{ml}$ syringe and 26 gauge needles. Fasting condition was maintained for 18 hours to induce diabetic condition in rat.

\section{Preparation of streptozotocin}

STZ was freshly prepared because it is unstable. It was administered in strength of dose: $60 \mathrm{mg} / \mathrm{kg}^{8}{ }^{8}$ For this, 480 $\mathrm{mg}$ of STZ powder was dissolved in $40 \mathrm{ml}$ of freshly prepared ice cold $0.1 \mathrm{M}$ citrate buffer, so that $1 \mathrm{ml}$ contained $12 \mathrm{mg}$ of STZ required for 200 gram of rat. This solution of STZ was titrated according to the required total dose per animal and was administered intraperitoneally using $1 \mathrm{ml}$ disposable syringe with 26 gauge needle.

\section{Preparation of nicotinamide}

Single dose of $120 \mathrm{mg} / \mathrm{kg}$ of nicotinamide was required for every rat (except group A) before streptozotocin administration. ${ }^{8} 2.4$ gram of nicotinamide powder was dissolved in $100 \mathrm{ml}$ of deionized water, so that $1 \mathrm{ml}$ contained $24 \mathrm{mg}$ of nicotinamide, required for 200 gram weight of rat. This solution of nicotinamide was titrated according to the required total dose per animal and was administered intraperitoneally using $1 \mathrm{ml}$ disposable syringe with 26 gauge needle.

Since this study requires type 2 diabetes mellitus model with moderate hyperglycemia (200-250 mg/dl), Masiello $\mathrm{P}$ et al introduced most acceptable and frequently used diabetic model of intraperitoneal injection of nicotinamide before streptozotocin induction of diabetes. $^{8,10}$

\section{Induction of diabetes mellitus}

Diabetes was induced by freshly prepared nicotinamide followed by streptozotocin by single intraperitoneal injection. For this, animals were deprived of food overnight and were allowed free access to water. Firstly, each animal of group B, C, D and E were administered nicotinamide $120 \mathrm{mg} / \mathrm{kg}$ intraperitoneally and then streptozocin $60 \mathrm{mg} / \mathrm{kg}$ was given to each animal of these groups after 15-20 minutes of nicotinamide administration. $^{8}$ Animals were held with its ventrum exposed and head pointed downward, this causes the freely movable abdominal organs to move towards the animal's diaphragm to avoid accidental puncture of organs. A $1 \mathrm{ml}$ disposable syringe with 26 gauge needle was inserted into the abdominal cavity in the lower right quadrant to avoid the caecum and urinary bladder. The needle was directed towards the animal's head at an angle of 15-20 degrees and inserted approximately $5 \mathrm{~mm}$. After induction, that animal were allowed to drink 5\% dextrose normal saline overnight to overcome the drug induced hypoglycemia. ${ }^{8,9}$

After 72 hours of streptozotocin injection, fasting blood glucose level was determined and induction of diabetes was confirmed. The diabetic rats were allowed access to tap water and normal laboratory diet freely, and were maintained at room temperature in their cages for next 4 days for stabilization of diabetes and acclimatization under these circumstances. The rats having blood glucose levels $200-250 \mathrm{mg} / \mathrm{dl}$ were used for the study.

\section{Statistical analysis}

Statistical analysis of data was carried out by employing analysis of variance. One way ANOVA test was used to compare the effect of drugs on different group the effect. Tukey's HSD test was used for post-hoc analysis of significant overall differences.

\section{RESULTS}

Streptozotocin induced diabetic rats showed reading in the range of $210-227 \mathrm{mg} / \mathrm{dl}$ which confirmed the induction of diabetes.

Fasting blood glucose in normal control (group A) was static. There was no much difference in blood sugar in different weeks in this group. Diabetic rats (group B) fasting blood glucose was $219.33 \pm 6.022$ at $1^{\text {st }}$ week and it was subsequently increased in different weeks. Fasting blood glucose in vidagliptin treated (group C) in first week was $216.17 \pm 7.574$ and it had a decreasing tendency to reach near normal blood sugar level. The animal of group D which was treated by voglibose orally also had a better control of FBS in comparison to diabetic control group. The animal of group $\mathrm{E}$ which was treated by coadministration of vildagliptin and voglibose had a better effect than group $\mathrm{C}$ and group $\mathrm{E}$ group animal. 
Table 1: Changes in FBS in all groups on $0,7^{\text {th }}, 14^{\text {th }}, 21^{\text {st }}$ and $28^{\text {th }}$ day. All the values are expressed in mean \pm standard deviation.

\begin{tabular}{|llllll|}
\hline Days & $\begin{array}{l}\text { Group A } \\
\text { (normal control) }\end{array}$ & $\begin{array}{l}\text { Group B } \\
\text { (diabetic control) }\end{array}$ & $\begin{array}{l}\text { Group C } \\
\text { (vildagliptin) }\end{array}$ & $\begin{array}{l}\text { Group D } \\
\text { (voglibose) }\end{array}$ & $\begin{array}{l}\text { Group E (voglibose and } \\
\text { vildagliptin) }\end{array}$ \\
\hline Day 0 & $83.33 \pm 1.751$ & $219.33 \pm 6.022$ & $216.17 \pm 7.574$ & $218.17 \pm 7.494$ & $218.33 \pm 7.062$ \\
\hline Day 7 & $84.33 \pm 3.204$ & $232.50 \pm 9.160$ & $137.50 \pm 5.891$ & $110.83 \pm 3.601$ & $103.67 \pm 7.230$ \\
\hline Day 14 & $84.50 \pm 2.345$ & $247.67 \pm 8.710$ & $129.17 \pm 5.115$ & $104.17 \pm 3.312$ & $95.83 \pm 6.706$ \\
\hline Day 21 & $84.00 \pm 1.095$ & $258.50 \pm 10.330$ & $121.17 \pm 5.345$ & $100.33 \pm 3.670$ & $89.83 \pm 5.492$ \\
\hline Day 28 & $84.67 \pm 1.366$ & $271.33 \pm 9.092$ & $115.83 \pm 5.636$ & $99.17 \pm 2.927$ & $88.67 \pm 6.683$ \\
\hline
\end{tabular}

The decline in FBS in group $\mathrm{C}$ was $36.4 \%$ on day 7 , $40.2 \%$ on day $14,43.94 \%$ on day 21 and $46.4 \%$ on day 28 .

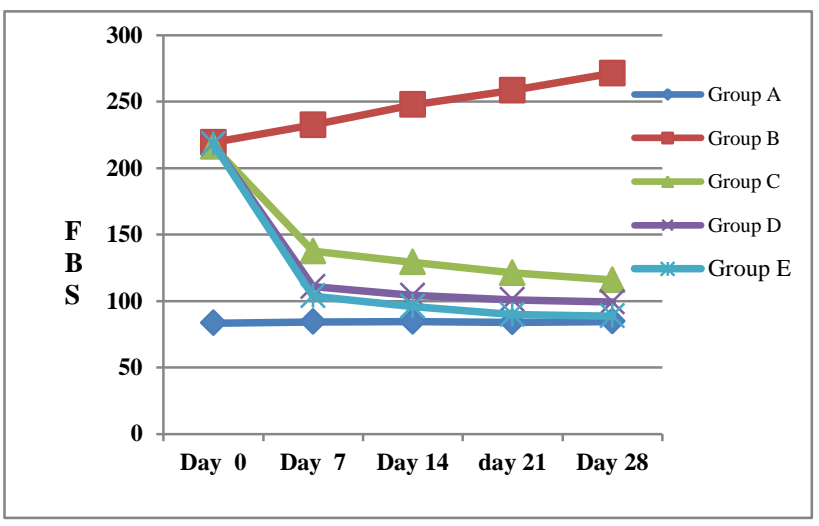

Figure 1: Changes in FBS in all groups on $0,7^{\text {th }}, 14^{\text {th }}$, $21^{\text {st }}$ and $28^{\text {th }}$ day.

Changes in FBS in all groups on $0,7^{\text {th }}, 14^{\text {th }}, 21^{\text {st }}$ and $28^{\text {th }}$ day. All the values are expressed in mean \pm standard deviation.

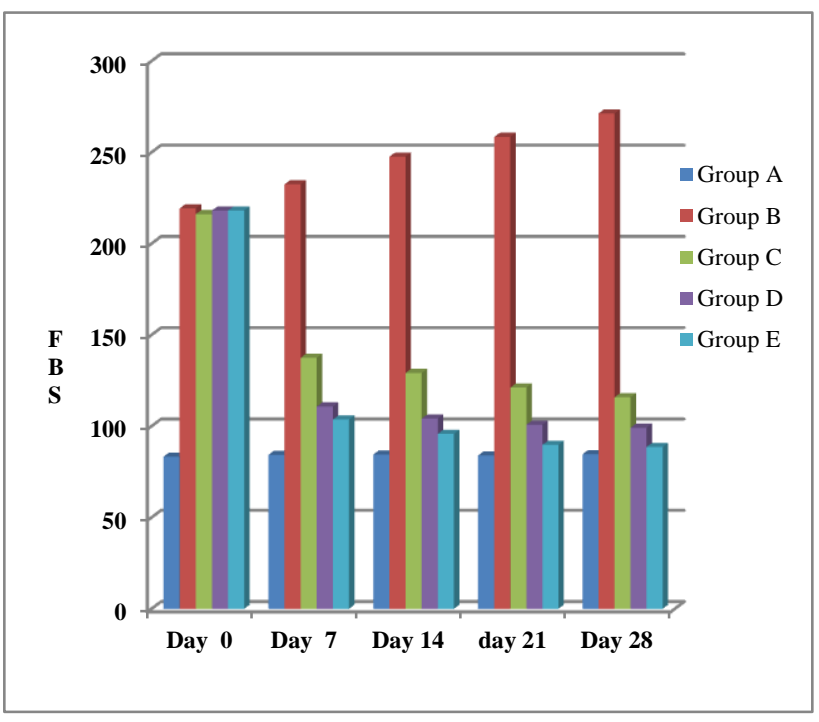

Figure 2: Antihyperglycemic effect in different treatment group in streptozotocin induced diabetic model albino rats.
Antihyperglycemic effect of voglibose and vildagliptin and their co-administration in streptozotocin induced diabetic model of albino rats.

The decline in FBS in group C was $36.4 \%$ on day 7 , $40.2 \%$ on day $14,43.94 \%$ on day 21 and $46.4 \%$ on day 28 . Group D shows FBS reading of moderate hyperglycemia on day 0 , further on day 7, 14, 21 and 28, the FBS gradually decreases. Here the reduction in FBS was $49 \%$ on day $7,52.25 \%$ on day 14 and $~ 54 \%$ on day 21 and 28 . Thus in group D rats, decline was maximal on day 7 and little fall was recorded on subsequent days. The reduction in mean FBS in group E was $52.5 \%$ on day $7,56 \%$ on day 14 and $59.4 \%$ on day 28. Maximum reduction of FBS was seen in this group.

\section{DISCUSSION}

Statistical interpretation of this study shows that vildagliptin have greater glucose lowering effect than voglibose. The co-administration of voglibose and vildagliptin has better efficacy than each individual drugs. Both drugs delay gastric emptying and reduce appetite due to enhanced GLP-1 activity. ${ }^{11}$ This may be the probable explanation of this potentiating effect of the coadministration of voglibose and vildagliptin. Yamaguchi M, Saji T, Mita $S$ et al also found that the most remarkable advantage of their co-administration was to increase beta cell mass and function. ${ }^{6}$

Vildagliptin, a dipeptidyl peptidase-1(DPP-4) inhibitor, decreases the inactivation of glucagon like peptide-1 (GLP-1) thereby increasing its secretion, accompanied with a decrease in that of glucagon. ${ }^{12,13}$ Important vildagliptin-induced beneficial effects in type 2 diabetes mellitus (T2DM ) include significant reduction in HB1 Ac (0.8-1.0\%) along with a reduction in fasting as well as postprandial plasma glucose. ${ }^{13-15}$ Similarly long term treatment of voglibose induces enteroendocrine cells which have potential contribution to the enhancing effect on plasma active GLP-1 contents in gastrointestinal tracts secreted during meal, so that endogenous GLP1 activity is unexpectedly found to be $\sim 1.6$ fold increase in the lower intestine and $\sim 1.4-1.6$ fold increase in colon. The increased active GLP-1 level in the colon has significant correlation with $\sim 1.4$ fold increase in gut gene expression 
levels of neurod 1 and $~ 2.6-3.1$ fold increase in glucagon, thereby increases the release of the glucoregulatory hormone glucagon like peptide-1 (GLP-1) into the circulation which contribute to their glucose lowering effect, may have boosting effect on the gliptins. ${ }^{16,17}$ Also Chronic administration of voglibose resulted in a $40-51 \%$ decrease in plasma DPP-4 activity. ${ }^{16}$ In clinical studies , alpha glucosidase inhibitors was found to reduce HBA1c by $0.5-0.8 \%$, fasting glucose by $\sim 1 \mathrm{~mm}$ and postprandial glucose by $2.0-2.5 \mathrm{~mm}$. $^{2}$

Yamaguchi M, Saji T, Mita S et al. also showed that their co-administration have better pharmacodynamic response in comparison to individual drug alone. They have shown that co-administration of vildagliptin and voglibose have synergistic effect on achieving adequate glycemic control. ${ }^{6}$

Potential antihyperglycemic effect together with achievement of glycemic target just in 7-21 days confirms their efficacy comparable to traditional antidiabetic agent. Maintenance of euglycemia throughout study not only proves their effectiveness but may also suggest beta cell (both mass and function) preserving role and their insulinotropic activity in diabetes mellitus. ${ }^{12,13}$ It was found to be safe oral preparation as mortality of animal was not seen during study period.

Despite of these prospective advantages, these drugs are still eluding researchers to recognize them as novel antidiabetic agents, as long term side effects are yet to be established.

In spite of its higher efficacy, long term effects and safety of vildagliptin and voglibose have to be established in clinical trials. The possibility of the combination therapy of vidagliptin with voglibose as a better pharmacologic molecule in refractory cases of type 2 diabetes mellitus need to be evaluated.

\section{CONCLUSION}

Combination effect of Vidagliptin and voglibose are much more efficacious then the individual drugs. Both the drugs are effective in lowering blood glucose level in albino diabetic rats but their combination has potentiating effect.

\section{Funding: No funding sources}

Conflict of interest: None declared

Ethical approval: The study was approved by the Institutional Ethics Committee

\section{REFERENCES}

1. Gobal prevalence of diabetes: estimates for the year 2000 and projections for 2030. Diabetic Care. 2004;27(5):1047-53.

2. Laurence LB, Bruce AC, Bjorn KC. Endocrine pancreas and pharmacotherapy of diabetes mellitus and hypoglycemia. In: Goodman and Gillman's Pharmacological Basis of Therapeutics: Alpha glucosidase inhibitor. 2012;43:1264-65.

3. Winker G. Incretin enhancers, incretin mimetics from therapeutic-control to clinical application. Ory Hetil. 2007;148:579-87.

4. Drucker DJ. Dipeptidyl peptidase-4 inhibition and the treatment of type 2 diabetes: preclinical biology and mechanism of action. Diabetes Care. 2007;30:133543.

5. Yamaguchi M, Saji T, Mita S, Kulmatycki K, He YL, Furihata K, et al. Pharmacokinetic and pharmacodynamic interaction of vildagliptin and voglibose in Japanese patients with type 2 diabetes. Int J Clin Pharmacol Ther. 2013;51(8):6414-5.

6. He H, Tran P, Yin H. Absorption, metabolism, and excretion of (14C) vildagliptin, a novel dipeptidyl peptidase 4 inhibitor, in humans. Drug Metab Dispos. 2009;37:536-44.

7. Ghosh MN. Toxicity studies. In: Ghosh MN, editor, Fundamentals of Experimental Pharmacology $5^{\text {th }}$ ed, Kolkata: Hilton and Company; 2011:167.

8. Nayak Y, Hillemane V, Daroji VK, Jayashree BS, Unnikrishnan MK. Antidiabetic activity of benzopyrone analogues in nicotinamidestreptozotocin induced type 2 diabetes in rats. The Scientific World Journal Volume. 2014;2014:854267.

9. Gandhi GR, Sasikumar P. Antidiabetic effect of merremia emarginata burm F. in streptozotocin induced diabetic rats. Asian Pac J Trop Biomed. 2012;2(4):281-6.

10. Masiello P, Broca C, Gross R, Roye M, Manteghetti M, Buys DH, et al. Experimental NIDDM: development of a new model in adult rats administered streptozotocin and nicotinamide. Diabetes. 1998;47:224-9.

11. Moritoh Y, Takeuchi K, Hazama M. Chronic administration of voglibose, an alpha-glucosidase inhibitor, increases active glucagon-like peptide-1 levels by increasing its secretion and decreasing dipeptidyl peptidase-4 activity in ob/ob mice. J Pharmacol Exp Ther. 2009;329(2):669-76.

12. Ahren B, Landin-Olsson M, Jansson P. Inhibition of dipeptidyl peptidase-4 reduces glycemia, sustains insulin levels, and reduces glucagon levels in type 2 diabetes. J Clin Endocrinol Metab. 2004;89:2078-84.

13. Mari A, Sallas M, He YL, Watson C, LiguerosSaylan M, Dunning BE, et al. Vildagliptin, a dipeptidyl peptidase IV inhibitor, improves modelassessed B-cell function in patients with type 2 diabetes. J Clin Endocrinol Metab. 2005;90:4888-94.

14. He YL, Sadler BM, Sabo R, Balez S, Wang Y, Campestrini J, et al. The absolute oral bioavailability and population-based pharmacokinetic modelling of a novel dipeptidyl peptidase IV inhibitor, vildagliptin, in healthy volunteers. Clinical Pharmacokinetics. 2007;46:787-802.

15. Sunkara G, Sabo R, Wang Y, He YL, Campestrini J, Rosenberg $\mathrm{M}$, et al. Dose proportionality and the 
effect of food on vildagliptin, a novel dipeptidyl peptidase IV inhibitor, in healthy volunteers. J Clinical Pharmacology. 2007;47:1152-8.

16. Katoaka Y, Yasuda S, Miyamota Y, Sase K, Kosuge $\mathrm{M}$, Kimura $\mathrm{K}$, et al. Effects of voglibose and nateglinide on glycemic status and coronary atherosclerosis in early stage diabetic patients.Circulation Journal. 2012;76(3):712-20.

17. Goke B, Fuder H, Wieckhorst G, Theiss U, Stridde E, Littke $\mathrm{T}$, et al. Voglibose (AO-128) is an efficient alpha-glucosidase inhibitor and mobilizes the endogenous GLP-1 reserve. Digestion. 1995(6);56:493-501.

Cite this article as: Keshri UPD, Kumar M, Loc BPD, Gari M, Sharma J, Kumar R. Effect of coadministration of voglibose and vildagliptin on diabetic albino rats. Int J Basic Clin Pharmacol 2016;5:1533-8 